\title{
PARAMETRIC STUDY ON TRANSVERSAL SLOPE AND SHORT-TERM DEFLECTION OF PRECAST SEGMENTAL BOX GIRDER CONDITIONS BY PERFORMING STATIC LOAD TEST
}

\author{
Fadzli Mohamed Nazri1* Mohd Azrulfitri Mohd Yusof ${ }^{2}$ \\ ${ }^{1}$ School of Civil Engineering, Engineering Campus, Universiti Sains Malaysia, Penang, Malaysia \\ 2Jambatan Kedua Sdn. Bhd, Jambatan Sultan Abdul Halim Mu’adzam Shah, Penang, Malaysia
}

Precast segmental box girders (SBGs) are a new innovative construction method that has been preferred for bridge construction in the past few decades, especially in Malaysia, given its many advantages. This study mainly aims to develop an experimental-analytical methodology that can be employed by researchers, designers, and engineers in determining the condition of precast SBG bridges by performing static load test before such bridges are opened to traffic. A short-term linear elastic analysis reasonably and realistically estimated vertical deflections, bending stresses, and bending strains that considered superimposed dead load, such as parapets. Results were compared with analytical predictions via finite element method using LUSAS software. The results obtained using the proposed methodology were compared in a parametric study, followed by a variety of transversal slopes or crossfall gradients of $0 \%, 2.0 \%, 2.5 \%$ and $3.0 \%$. The proposed methodology can accurately predict the displacements under different load cases. Moreover, stress plays a positive role in the probability effect of vertical displacement accuracy under the short-term and long-term analyses of long-span segmental bridges.

Key words: Bridging, Construction, Displacement, Loads, Segmentation, Tranverse

\section{INTRODUCTION}

The Second Penang Bridge is part of a traffic logistics connecting Batu Kawan and Batu Maung across the southern channel of the Penang Straits in Malaysia, as shown in Figure 1. The total length of the highway is approximately $24 \mathrm{~km}$, which is considered the longest bridge in Southeast Asia with a total length of $16.9 \mathrm{~km}$ over water with dual carriageway and dedicated motorcycle lane. To meet public demands, the Second Penang Bridge was opened to traffic on March 1, 2014. The bridge was officially named Jambatan Sultan Abdul Halim Mu'adzam Shah after the 14th Yang di-Pertuan Agong, Tuanku Abdul Halim Mu`adzam Shah of Kedah. The logistical, quality, environmental, safety, and health factors were the challenges encountered specifically for the superstructure work activities in this project. A typical viaduct of precast segmental box girder (SBG) in the Second Penang Bridge Project is shown in Figure 2.

In view of segmental bridge technology, producing bridge segments in a casting yard away from the bridge construction site provides numerous advantages over cast-in-place concrete [04]. Superstructures built based on precast SBG would ensure high level of quality assurance or quality control (QA/QC) during construction stage. Thus, it is important to assess the integrity of the bridge based on established field load testing either by static or dynamic load test with effective instrumentations for monitoring of construction control and maintenance before opening to traffic, as reported by [02], [05] reported that the construction quality, structural performance, and actual load carrying capacity of the bridge to be re- built or strengthened can be determined and analyzed by static load test to provide guide information. The static load testing in the Second Penang Bridge involved arrangement of mass concrete blocks, installation of strain gauge instrumentation inside SBG, and deck survey via precise leveling to measure absolute reduce level ( $R L)$ and deflections over the bridge on selected span. The data collected was analyzed and used to compare a working finite element method (FEM) under a short-term analysis. Furthermore, a variety of transversal slopes were considered to investigate the deflection, stress, and strain behaviors. This research aimed to analyze the elastic behavior of erected precast SBG subjected to experimental static load test and to specify the maximum deflection, stress, and strain values of single-span precast SBG by FEM under a variety of transversal slopes.

\section{BRIDGE DESCRIPTION}

\section{Project Overviews}

In this study, the selected precast SBG's span was subjected to basic casting yard procedures, routine inspection, and monitoring. The effectiveness of bridge casting yard procedures, bridge design, and maintenance can be improved by gaining a better understanding the mechanisms of bridge deterioration and by investigating the behavior of erected precast SBG's span subjected to static load. 


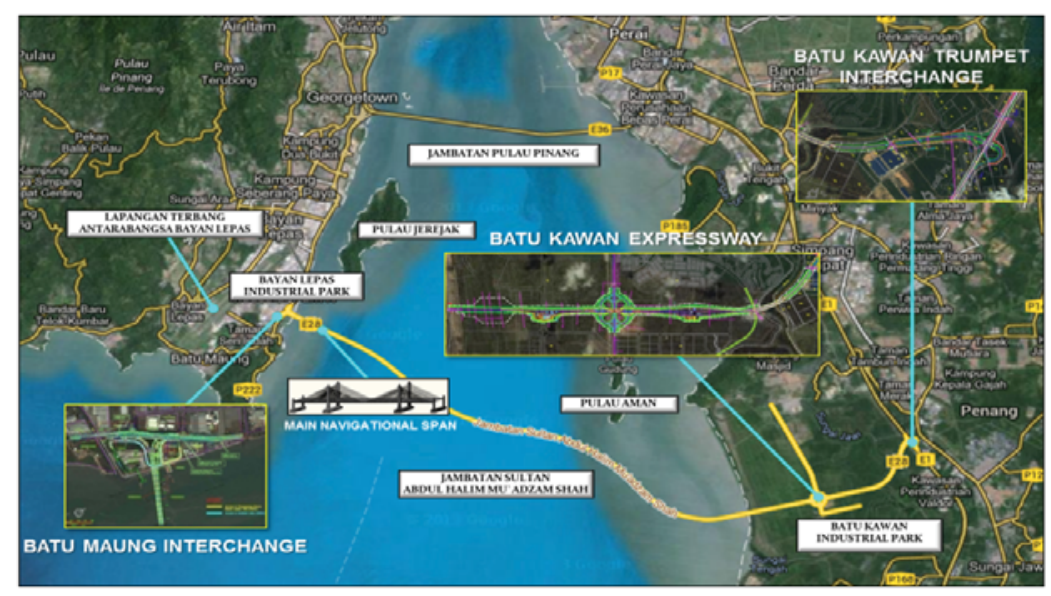

Figure 1: The Second Penang Bridge project alignment
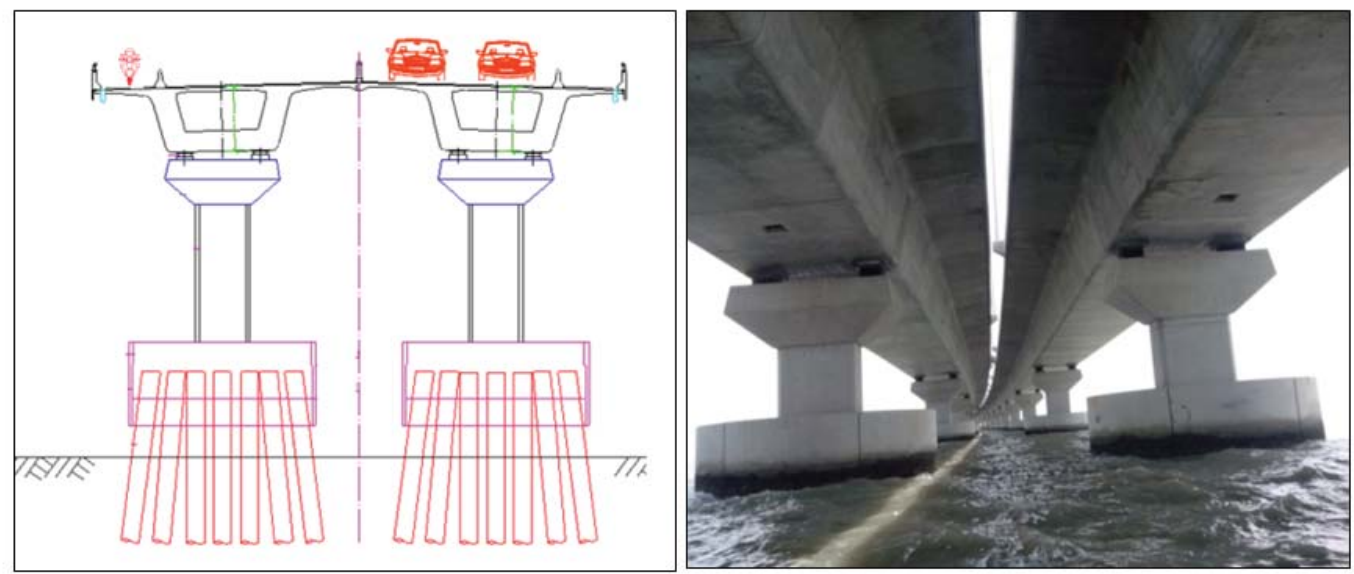

Figure 2: Viaduct for the Second Penang Bridge

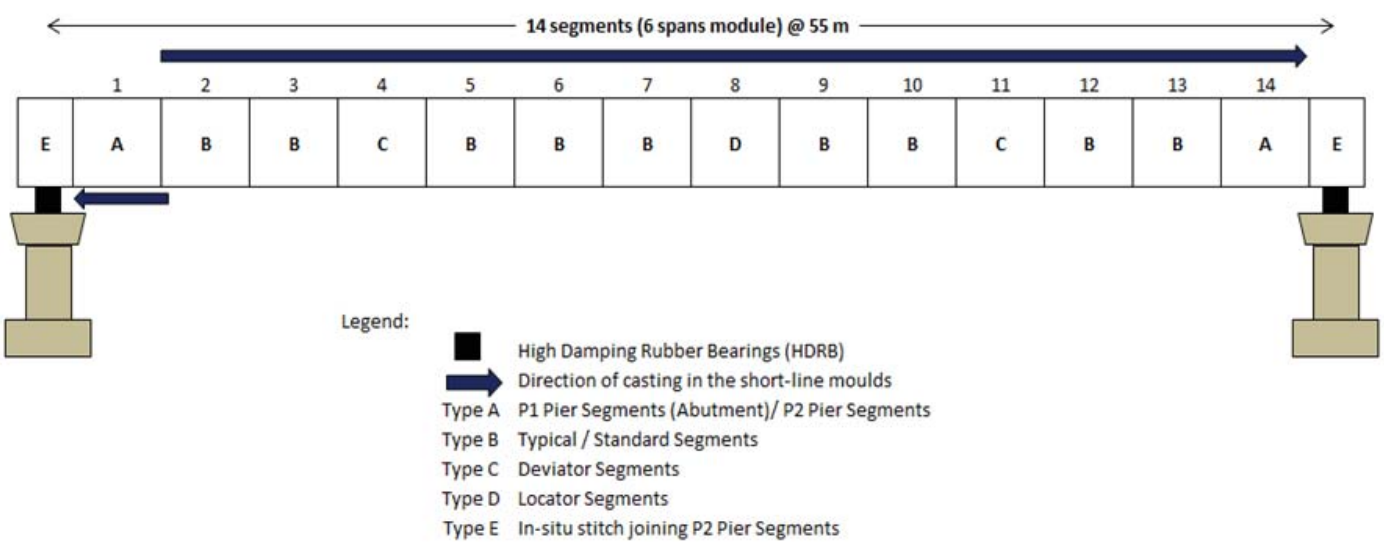

Figure 3: Typical precast SBG bridge span 
Static load test is frequently used before opening a new large bridge to verify its actual structural behavior compared with that predicted by theory or conventional method. However, the testing and modeling of precast SBG is not a simple but a complex and tricky work. There had been numerous studies that examined the behavior of SBG bridges. The Second Penang Bridge superstructure consists of 289 spans of $55 \mathrm{~m}$ nominal length side-by-side precast SBG and contains a total of 14 segments, which include nine typical segments, two deviator segments, two pier or abutment segments, and one locator segment. The precast SBGs with a weight range of around 69 tons to 110 tons were erected as simply supported spans through span-by-span method. The segment width varies from $2.65 \mathrm{~m}$ to $4.1 \mathrm{~m}$ with a $1.4 \mathrm{~m}$ long cast in-situ stitch at the pier locations. The bridge depth is $3.2 \mathrm{~m}$. The deck spans were divided into five standard segment types. Figure 3 shows the typical precast SBG bridge span.

\section{LOAD TEST EXECUTION AND DATA ACQUISITION}

\section{Survey Points and Load Test Arrangement}

The deck surveys to measure absolute RL and deflections of survey bolts were taken using a single staff and a pair of digital level instruments namely Instrument $X X$ and Instrument $Y Y$ with a single back sight temporary bench mark (TBM) on a pier segment of the North Span adjacent to the South Span under test. The deflection measurements at selected joints were taken to measure the span deformation such as vertical deflections. These may be accurately measured by means of surveying cast-in alignment control survey bolts or so-called embedded round-head survey bolts using accurate digital leveling equipment. The sketch of load application operation and deck deflections monitoring is shown in Figure 4.

The static load cases were simulated using up to 50 number precast mass concrete blocks with approximate dimensions of $1 \mathrm{~m} \times 1 \mathrm{~m} \times 1 \mathrm{~m}$ and represented HA (normal) and HB (abnormal) loadings which were proposed to generate span deformation tests for the structural performance of the deck structure and monitoring of movements simulating wind and live load actions. The average weight of the blocks was 2.4 tons. In this study, deck deflection measurements were taken including the baseline readings, the three load cases readings under Load Case 1 (LC1@HA-UDL), Load Case 2 (LC2@HB-30), and Load Case 3 (LC3@HA-KEL), and the final unloaded case readings after removing the blocks upon completion of the load tests to confirm the elastic return. The loading operations were carried out as quickly as possible to minimize the temperature effects on the deck. When the tolerance exceeded $\pm 1 \mathrm{~mm}$, readings from both Instrument $X X$ and Instrument $Y Y$ were recorded again. LC1, which mainly examined the capacity of maximum displacement in the mid-span area and simulated using 50 blocks placed over the top of one web as one lane over the full length of the span, had an approximate weight of $1200 \mathrm{kN}$. LC2, which mainly examined the capacity of maximum displacement in the mid-span area and simulated using 50 blocks placed over the top of one web as two lanes over the central section of the span, had an approximate weight of $1200 \mathrm{kN}$. However, LC3 was simulated using 17 blocks placed over the two central segments and had an approximate weight of $408 \mathrm{kN}$.

Baseline surveys were taken at 9am, 12pm, 3pm, and $6 \mathrm{pm}$ to allow the deck to respond to temperature effects during the day. Moreover, deflections under three load cases could be determined by comparing readings taken at the specified load cases time similar to those taken for the baseline readings. From the unloaded case 1 and unloaded case 2 readings, the differences in time were minimal based on the change of deck elevations recorded.

\section{Strain Gauges Installation}

In this study, only the strain gauge arrangement at midspan was considered. The gauges and data logging equipment were installed with the gauges secured to the concrete surfaces using epoxy. The strain gauge used in the load test was a $150 \mathrm{~mm}$ vibrating wire type gauge with an operational range of $3000 \mu \varepsilon$. The microstrains $(\mu \varepsilon)$ measured and the associated stresses in the deck at specific locations can be calculated using the value of Modulus of Elasticity $(E)$ established for the in-situ concrete. Vibrating Wire Strain Gauges (VWSG) were installed on the web (VWSG3), bottom slab (VWSG5), and bottom top slab (VWSG7) in the inner side of the bridge at locations 3,5 , and 7 . The sketch and installation of VWSG at mid-span area are shown in Figure 5 and Figure 6 ( $a, b, c$ and $d)$.

\section{FINITE ELEMENT METHOD}

\section{Attributes and Validation of FEM}

Most of the designers, engineers, and practitioners agreed that FEM is the most powerful, versatile, and flexible method. A complex geometry such as the precast SBG can be readily modeled using FEM. The method can deal with different material properties, relationships between structural components, boundary conditions, as well as statically or dynamically applied loads. Viaducts of six spans were modeled with nodes in every segment joint. Member properties of different elements were calculated as the average of properties at the start and end joints. The roller supports were modeled in every permanent bearing and one pinned support was utilized to stabilize the model. The pre-stress was designed to maintain zero tension across the entire precast joint under serviceability limit state (SLS).Three-dimensional (3-D) solid elements were employed to analyze the complex behavior of different load cases. Linear analysis was carried out for the dead load (self-weight), superimposed dead load (parapets loading), and three live load conditions. 
All the dimensions such as webs, flanges, diaphragms, top and bottom slabs followed the specification and the approved as-built drawing belonging to the owner of this project.

For this study, the right method of modeling is important because it will affect the results and prevent the occurrence of systematic errors. Therefore, the basic knowledge and information in modeling must be clearly understood and correctly implemented to assure the accuracy and quality of data. Before conducting a parametric study such as the deflections under a variety of transversal slopes, the FEM model was validated using a recent experimental data for a selected span. The FEM model was divided into several sections based on type of precast SBG with each section having the same material properties except parapets. These sections included the deck, bottom flange, web girders, and diaphragms. Furthermore, these values as well as boundary conditions that were changed until a strong correlation between the FEM model and the static load test data was found have been discussed further. The perfect bonds between solid elements were assumed, such that two elements sometimes shared the same nodes. In this model, the separate models which contained different types of SBG including in-situ stitch segments were combined and assembled again.

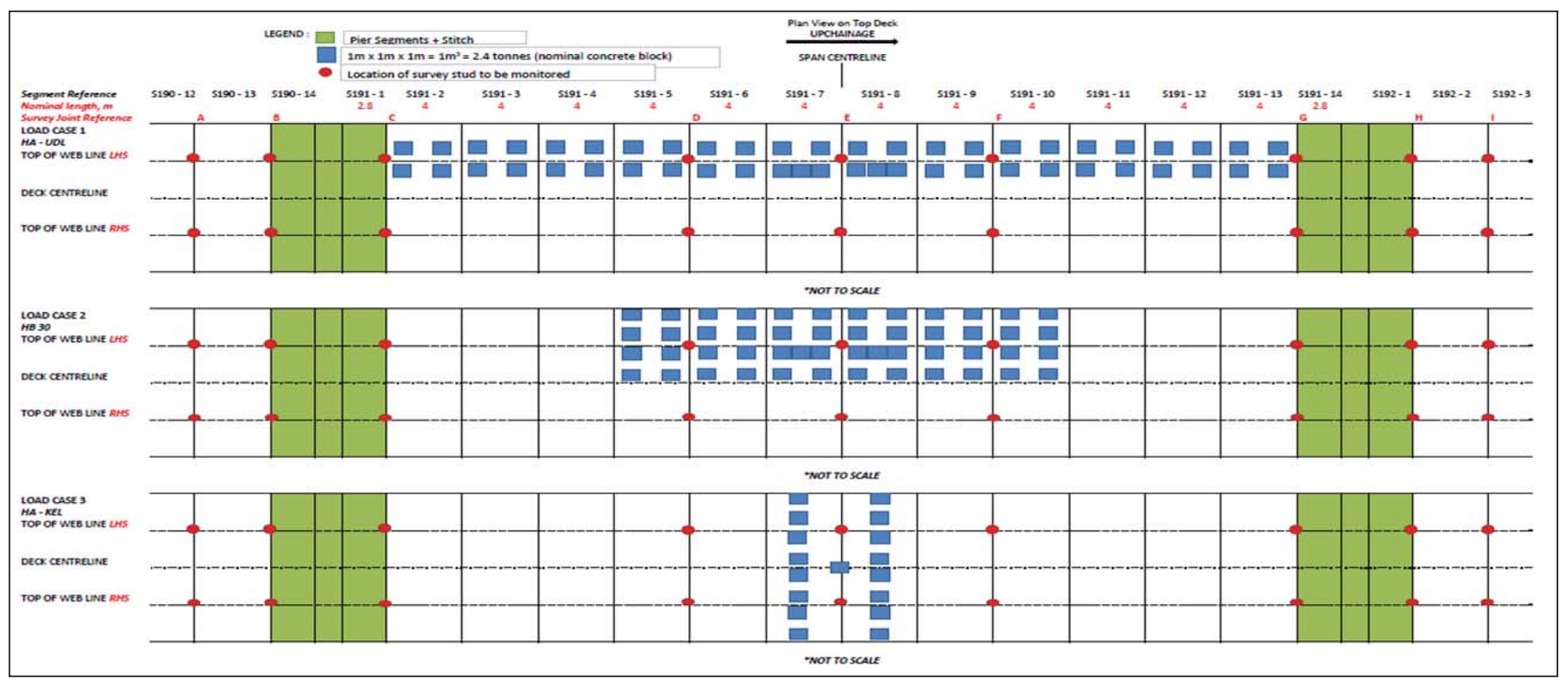

Figure 4: Sketch of load application operation and deck deflections monitoring

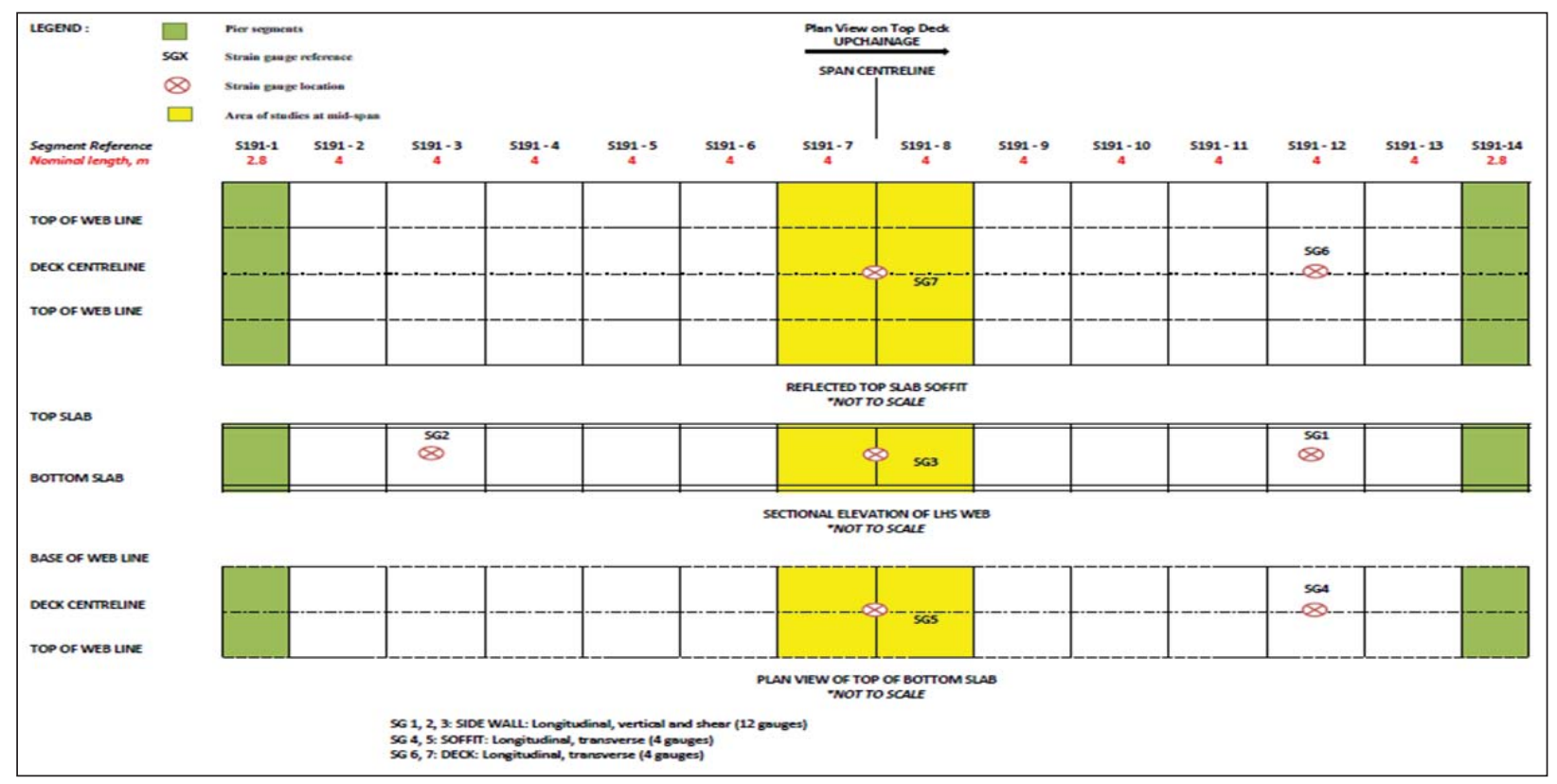

Figure 5: Sketch of VWSGs installation at mid-span area 


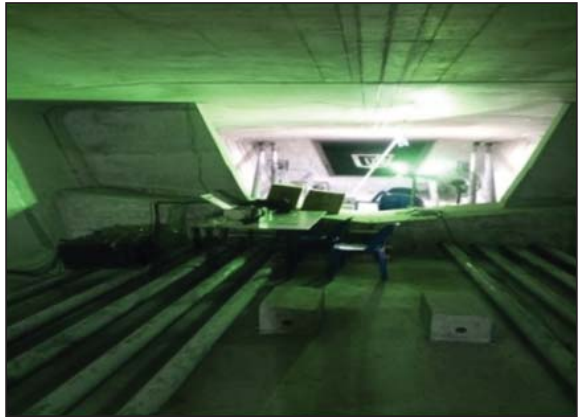

a)

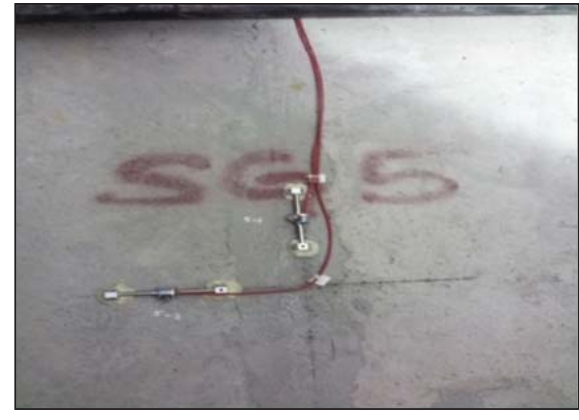

c)

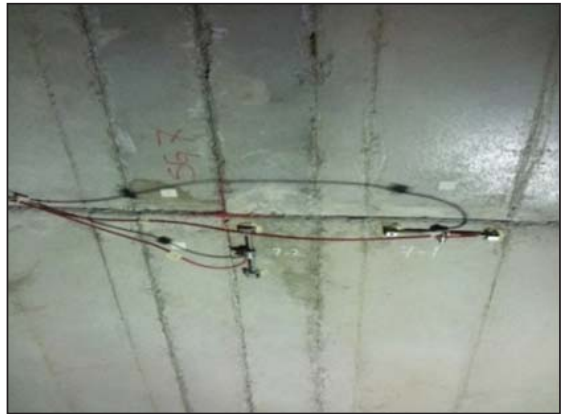

b)

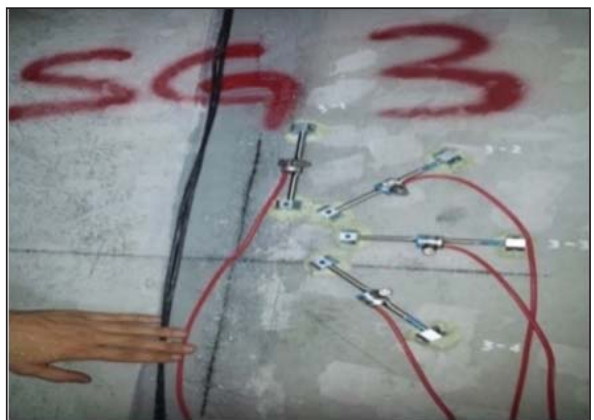

d)

Figure 6: Installation of Vibrating Wire Strain Gauges (VWSGs) at mid-span area; (a) Data logging equipment set up at desk; (b) Bottom top slab gauge arrangement at SG7; (c) Bottom slab gauge arrangement at SG5; and (d) Web gauge arrangement at SG3

After completing the geometry model, meshing was assigned to the geometry using line and volume mesh for tendon profile and SBGs designs. Mesh describes the element type and discretization on the geometry. Irregular mesh was used in volume mesh to comply the span to depth ratio in the model while tetrahedral element shape and linear interpolation order were also used in the volume mesh. The materials used for the precast SBG elements were concrete grade short-term C50 from BS 5400 while ungraded stainless steel was used for tendon elements. The concrete grade complied with the strength requirement for actual casting in segmental bridge construction. The tendon profile was defined as a spline. Sufficient points must be used in line definition to accurately represent the tendon profile as a series of straight lines or curve lines. Moreover, if a tendon (external or internal) is included in the analysis model, thick beam elements are assigned to the lines defining the tendon profile and the concrete beam surrounding the tendon is modeled with plane stress or 3-D solid elements. Using this simplified force approach, the effects of pre-stress can be defined in a separate linear load case that can be combined with other load cases to compute the overall structural behavior. Fixed support was applied in three nodes at both bottom end of the box girder to withstand the applied load and to observe the deflection attributed to its application. Then, the structural load was assigned. In this study, global distributed load [03] was applied at the top surface of the deck as shown in Figure $7(a, b$ and $\mathrm{c}$ ).

\section{Parametric Study on Transversal Slope}

In order to ensure that the FEM analysis results were in good agreement with the experimental data and theoretical calculation, all meshed models of precast SBG with a variety of transversal slope $0 \%, 2.0 \%, 2.5 \%$, and $3.0 \%$ were intended to achieve efficient removal of water from carriageway which take into account the superimposed dead load such as parapets in the design compared with analytical predictions using LUSAS. In those systems, the transversal sections of an object developed along a longitudinal axis were always generated on an orthogonal orientation in relation to the longitudinal axis as shown in Figure 8 (a, b, c and d). The generation of 3-D FEM meshing was also needed to obtain the correct configuration (interior and exterior) of a box girder deck.

\section{RESULTS AND DISCUSSION}

\section{Elastic Behavior of Precast SBG}

The bridge in the unloaded case 1 was monitored for 24 hours as reference in determining the effects of thermal-induced microstrain. The effects of temperature on a precast segmental bridge superstructure are similar to that of any bridge superstructure in the longitudinal direction. 


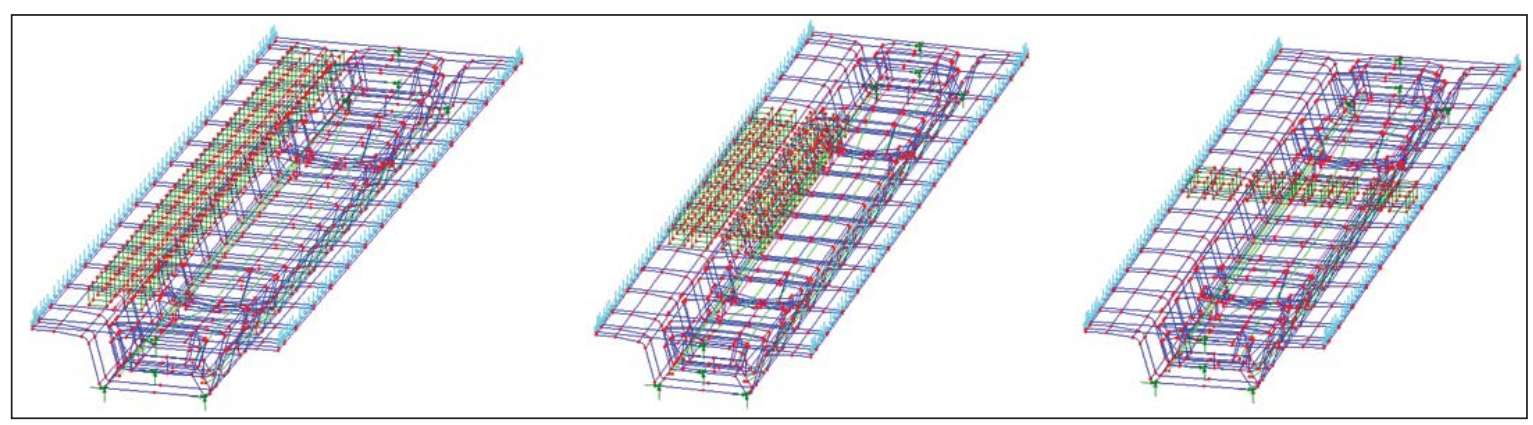

a) b) c)

Figure 7: FEM model representation of three load cases; (a) LC1; (b) LC2; and (c) LC3

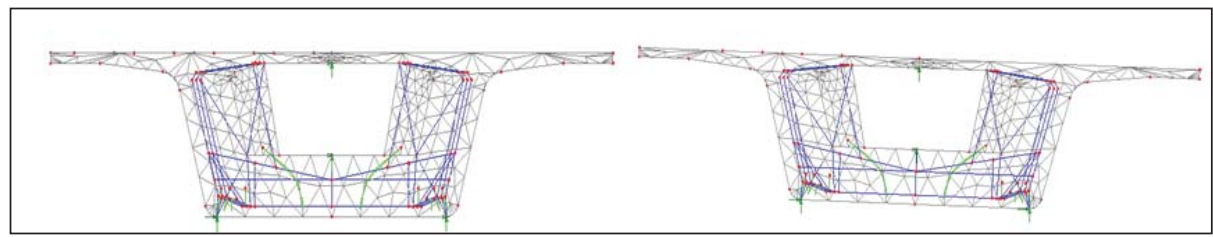

a)

b)

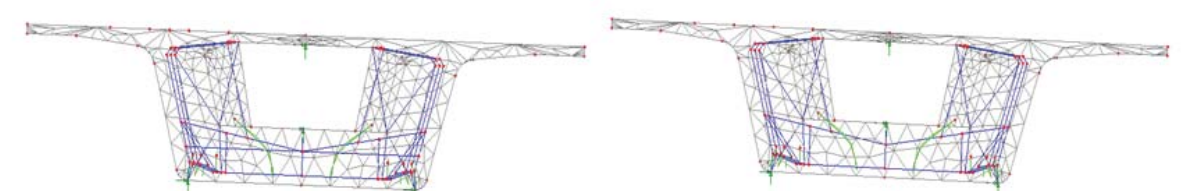

c)

d)

Figure 8: Meshed model of precast SBG with a variety of transversal slope:

(a) $0 \%$; (b) $2.0 \%$; (c) $2.5 \%$; and (d) $3.0 \%$

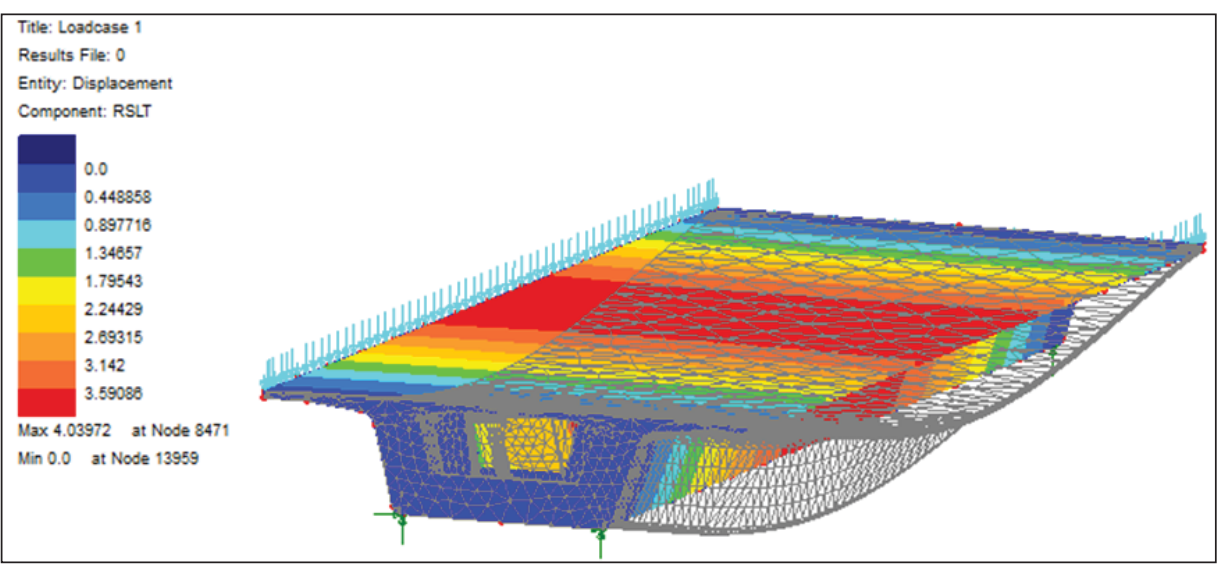

Figure 9: Deflection analysis by FEM under LC1 with 2.5\% transversal slope 
The study on elastic behavior of precast SBG showed that the experimental method was carried out successfully. The recorded strain monitoring data showed the strain and temperature profiles against time at mid-span area where the web, top, and bottom slab temperature increased and decreased with respect to time and strain of the box sections. After completion of the three load cases, all concrete blocks were removed and the bridge was monitored in the unloaded case 2 for another 24 hours. The selected single span had responded to the specific load cases and subsequent unloading and measured behaviors and values were very similar to the predicted values. The return of the observed values to original values after the static load test confirmed the elastic behavior of the deck. To investigate the variation of strain gauges value, the VWSG were randomly identified (see Table 1). The strain gauge data showed a cyclic response of the structure to thermal variations during the day and night.

Table 1: Strain $(\mu \mathcal{E})$ and temperature $\left({ }^{\circ} \mathrm{C}\right)$ for unloaded case 1 and unloaded case 2

\begin{tabular}{|c|c|c|c|}
\hline VWSGs & Parameter & $\begin{array}{c}\text { Unloaded } \\
\text { Case 1 }\end{array}$ & $\begin{array}{c}\text { Unloaded } \\
\text { Case 2 }\end{array}$ \\
\hline \multirow{2}{*}{ *VWSG3-3 } & Strain $(\mu \varepsilon)$ & 27.0 & 28.3 \\
\cline { 2 - 4 } & ${ }^{\circ} \mathrm{C}$ & 33.25 & 31.64 \\
\hline \multirow{2}{*}{ *VWSG5-1 } & Strain $(\mu \varepsilon)$ & 13.85 & 11.06 \\
\cline { 2 - 4 } & ${ }^{\circ} \mathrm{C}$ & 30.61 & 29.56 \\
\hline \multirow{2}{*}{ *VWSG7-2 } & Strain $(\mu \varepsilon)$ & 38.8 & 34.97 \\
\cline { 2 - 4 } & ${ }^{\circ} \mathrm{C}$ & 33.1 & 31.91 \\
\hline
\end{tabular}

*VWSG3-3 - Strain gauge number 3 at web in longitudinal direction;

*VWSG5-1 - Strain gauge number 5 at bottom slab in transverse direction; and

*VWSG7-2 - Strain gauge number 7 at bottom top slab in longitudinal direction.

\section{Comparison with Deflection}

The results of LUSAS analysis showed that maximum displacement occurred at the mid-span area of SBG. The red color in Figure 9 shows the critical displacement on deflection analysis by FEM under LC1 with $2.5 \%$ transversal slope. The middle part of the single span SBG where the maximum displacement occurred was the critical part. Furthermore, this situation was equivalent to the case of precast SBG during the real construction process, wherein the middle part is its most critical component. FEM analysis proved that modeling considered the boundary constraints, namely null vertical displacements over the supports and null curvatures over the outer supports while the experimental curvatures were derived from precise leveling readings. Thus, the deflection of a precast SBG span was highly influenced by the behavior of cross-sections near the mid-span and support zones.
Only $2.5 \%$ of transversal slope was considered as per actual span erected on site. The geometric components of the precast SBG such as horizontal alignment (z-axis), vertical alignment ( $y$-axis), and transversal alignment (x-axis) were also considered in this study. The FEM displacement data were close to the experimental data as compared with $0 \%$ of transversal slope. However, most of the designers and engineers preferred to use traditional method due to small percentage errors. The comparison between the FEM and measured displacements from the static load test can be seen in Figure 10. $(a, b$ and $c)$. From these figures, it was evident that an excellent correlation existed between the deflection values from FEM, the static load test experimental data, line beam method (LBM), and theoretical calculation.

It can be observed that the actual deck responses under the three load cases were very similar to each respective theoretical expected deflections allowing for accuracy of the precise leveling and the theoretical values as reflected in both the patterns and the values. Furthermore, FEM is an acceptable method to obtain displacements and reactions for simply supported precast SBG under short-term analysis. The displacements obtained by FEM compared with the experimental measures resulted in percentage errors which in the majority of the load cases were within $10 \%$. The structural model of bridges constructed using simply supported method must adhere to the changes of boundary conditions. It should be emphasized that pre-stressing and parapets were completed but the pavement works had not yet started during the static load test and this should be considered depending on the current situation on site. Therefore, the underestimation of deflections would be quite significant if ignored. It was also proven that when a member was assumed and designed to be un-cracked under full load, a simple linear elastic analysis based on gross cross-section was sufficient to give reasonable and realistic estimate of deflections.

According to the Design Manual for Roads and Bridges, TA/99 Volume 4 Section 2 (1999) for surface drainage of wide carriageways has mentioned via Clause 2.7 under effect of water on carriageway surfaces that "The UK standard minimum crossfall is $2.5 \%$. This is one of the higher national standards and is intended to achieve efficient removal of water from carriageways, including undulations caused by rutting. Superelevated sections will generally have crossfalls equal or greater than $2.5 \%$, however, areas of low crossfall will occur at superelevation rollovers." Referring to the parametric study for the different transversal slopes under maximum deflection along the span length of precast SBG, the values obtained for $0 \%, 2.0 \%, 2.5 \%$, and $3.0 \%$ of transversal slope showed a slight difference between them. The calculated percentage error ranged from $0 \%$ to $10.28 \%$ under $2.5 \%$ transversal slope. As shown in Table 2, the percentage error ranges that were less than $10 \%$ were considered acceptable. It can be concluded that the segmental bridge orientation was the stiffest among the four trans- 
versal slopes and the 3-D deck models cross-section will correctly define the shape, orientation, and position over the traditional method. Thus, it should be noted that the difference in transversal slope would affect the vertical displacements under short-term analysis and probably for deflection under long-term performance.

\section{Stress and Strain Analysis at Mid-span for 2.5\% Transversal Slope}

Stress had an important role in precast SBG because it can affect the durability and strength of the structure. Higher stress will reduce the performance of a single span of precast SBG; thus, the stress at mid-span area is important to be controlled. Stress also affected the value of shear capacity but it was not discussed in this study. Stress and strain developed from the action of the load applied to the segment because of distortion of the members. A graphical comparison under $2.5 \%$ transversal slope was studied in terms of vertical bending stress (VBstress), longitudinal bending stress (LBstress), and transverse bending stress (TBstress) along the span across the cross-section on top, bottom and web sections at mid-span area for live load effects. The LBstress in bottom slab at mid-span area had the highest value of $2.33 \mathrm{~N} / \mathrm{mm}^{2}$ followed by LBstress in web with -0.81 $\mathrm{N} / \mathrm{mm}^{2}$ and $-1.24 \mathrm{~N} / \mathrm{mm}^{2}$ in bottom top slab. The TBstress in bottom top slab had the highest value of $0.99 \mathrm{~N} /$ $\mathrm{mm}^{2}$, followed by the bottom slab with $0.54 \mathrm{~N} / \mathrm{mm}^{2}$, while VBstress in web was $0.45 \mathrm{~N} / \mathrm{mm}^{2}$. From the calculated bending stress distribution, it can be concluded that in case of dead load and live load, effects during static load test was $22.1 \%$ higher in percentage error compared to FEM.

The bending strains versus time curves showed variation of longitudinal bending strain (LBstrain), transverse bending strain (TBstrain), and vertical bending strain (VBstrain) across the cross-section in bottom top slab, bottom slab, and the web. Figure11 to Figure14 shows a variation of LBstrain using experimental technique and FEM. The strain gauges data output showed a cyclic response of the structure to thermal variations during testing. The data was recorded at a rate of one sample per minute per channel and stored on the data logger. The LBstrain in bottom slab at mid-span area had the highest value of $42.64 \mu \varepsilon$ followed by LBstrain in web with $-14.76 \mu \varepsilon$ and $-22.63 \mu \varepsilon$ in bottom top slab respectively. TBstrain in bottom top slab had the highest value of $18.04 \mu \varepsilon$, followed by the bottom slab with $9.82 \mu \varepsilon$, while VBstrain in web was $8.21 \mu \varepsilon$. From the calculated bending strain distribution, it can be concluded that in case of dead load and live load, effects during static load test was $15.8 \%$ higher in percentage error compared to FEM. Based on the measured deck stresses and strains, it can be concluded that the selected single span had responded to the specific load cases and subsequent unloading with measured behaviors and values that were very similar to the predicted value.

Furthermore, data collected during load test measurement was useful to assess the precast SBG's behavior as well as to evaluate the performance of the bridge under short-term observation. Table 3 shows a comparison of maximum bending stress and strain by experimental and FEM at mid-span area.

For all transversal slopes, the maximum stress and strain at the support conditions showed that $2.0 \%$ transversal slope was the highest with $31.7 \mathrm{~N} / \mathrm{mm}^{2}$ and $1.09 \mu \varepsilon$, respectively. Moreover, the maximum stress and strain for all transversal slopes were almost equal to zero at mid-span area. It showed that an increase in stress of precast SBG resulted to the corresponding increase in strain. From Table 4 under LC1, it can be concluded that, when the transversal slope was increased from $0 \%$ to $2.0 \%$, the maximum mid-span deflection along the longitudinal direction increased by $7 \%$, and maximum stress and strain at support condition also increased by 18.16 $\mathrm{N} / \mathrm{mm}^{2}$ and $0.63 \mu \varepsilon$, respectively. However, when the transversal slope was increased from $2.0 \%$ to $2.5 \%$, the deflection decreased by $8.2 \%$ while the maximum stress and strain at support condition also decreased by 14.29 $\mathrm{N} / \mathrm{mm}^{2}$ and $0.49 \mu \varepsilon$, respectively. Lastly, when the transversal slope was increased from $2.5 \%$ to $3.0 \%$, the deflections increased by $1.5 \%$ while the maximum stress and strain at support condition decreased by $2.42 \mathrm{~N} / \mathrm{mm}^{2}$ and $0.09 \mu \varepsilon$, respectively.

Table 2: Experimental results vs. FEM approach under maximum deflection at different transversal slope (unit: $\mathrm{mm}$ )

\begin{tabular}{|c|c|c|c|c|c|c|c|c|c|}
\hline \multirow{4}{*}{$\begin{array}{c}\text { Transversal } \\
\text { Slope }\end{array}$} & \multicolumn{9}{|c|}{ Load Cases } \\
\hline & \multicolumn{3}{|c|}{ LC1 } & \multicolumn{3}{|c|}{$L C 2$} & \multicolumn{3}{|c|}{$L C 3$} \\
\hline & \multicolumn{9}{|c|}{ Maximum Displacement (mm) } \\
\hline & Exp. & FEM & Error (\%) & Exp. & FEM & Error $(\%)$ & Exp. & FEM & Error (\%) \\
\hline $0 \%$ & -3.954 & -4.087 & 3.36 & -6.346 & -5.509 & -13.20 & -1.459 & -1.631 & 11.79 \\
\hline $2.0 \%$ & -3.954 & -4.363 & 10.36 & -6.346 & -5.511 & -13.17 & -1.459 & -1.638 & 12.27 \\
\hline $2.5 \%$ & -3.954 & -4.040 & 2,17 & -6.346 & -5.425 & -14.51 & -1.459 & -1.609 & 10.28 \\
\hline $3.0 \%$ & -3.954 & -4.100 & 3.71 & -6.346 & -5.478 & -13.68 & -1.459 & -1.627 & 11.54 \\
\hline
\end{tabular}


Table 3: Comparison of maximum bending stress and strain at mid-span area obtained through experiment and FEM

\begin{tabular}{|c|c|c|c|c|}
\hline \multirow{2}{*}{ Vibrating Wire Strain Gauge (VWSG) } & $\sigma_{\max }$, Exp. & FEM & $\varepsilon_{\text {max }}$, Exp. & FEM \\
\hline & \multicolumn{2}{|c|}{$\left(\mathrm{N} / \mathrm{mm}^{2}\right)$} & \multicolumn{2}{|c|}{$(\mu \varepsilon)$} \\
\hline *VWSG3-3 (Web) & -0.81 & -1.90 & -14.76 & -24.4 \\
\hline "VWSG5-2 (Bottom) & -1.24 & -0.95 & -22.63 & -48.8 \\
\hline *VWSG7-2 (Top) & 2.33 & 1.90 & 42.64 & 48.84 \\
\hline *VWSG5-1 (Bottom) & 0.99 & $-2.2 E-16$ & 18.04 & 0 \\
\hline${ }^{*}$ VWSG7-1 (Top) & 0.54 & $2.2 \mathrm{E}-16$ & 9.82 & 8.22 \\
\hline *VWSG3-1 (Web) & 0.54 & 0.63 & 8.21 & 20.86 \\
\hline
\end{tabular}

${ }^{*} V W S G 3-1$ - Strain gauge number 3 at web in vertical direction; *VWSG3-3 - Strain gauge number 3 at web in longitudinal direction; *VWSG5-1 - Strain gauge number 5 at bottom slab in transverse direction; *VWSG5-2 - Strain gauge number 5 at bottom slab in longitudinal direction; ${ }^{*}$ VWSG7-1 - Strain gauge number 7 at bottom top slab in transverse direction; *VWSG7-2 - Strain gauge number 7 at bottom top slab in longitudinal direction

Table 4: Comparison of maximum stress and strain under LC1 by using FEM

\begin{tabular}{|c|c|c|c|c|}
\hline Maximum Stress, $\sigma_{\max }$ and Strain, $\varepsilon_{\max }$ & \multicolumn{4}{|c|}{ Transversal Slope (\%) } \\
\hline Stress, $\sigma_{\max }\left(\mathrm{N} / \mathrm{mm}^{2}\right)$ & $0 \%$ & $2.0 \%$ & $2.5 \%$ & $3.0 \%$ \\
\hline At mid-span & 0.00 & 0.00 & 0.00 & 0.00 \\
\hline At support condition & 13.54 & 31.70 & 17.41 & 14.99 \\
\hline Strain, $\varepsilon_{\max }(\mu \mathcal{E})$ & $0 \%$ & $2.0 \%$ & $2.5 \%$ & $3.0 \%$ \\
\hline At mid-span & 0.00 & 0.00 & 0.00 & 0.00 \\
\hline At support condition & 0.46 & 1.09 & 0.60 & 0.51 \\
\hline
\end{tabular}

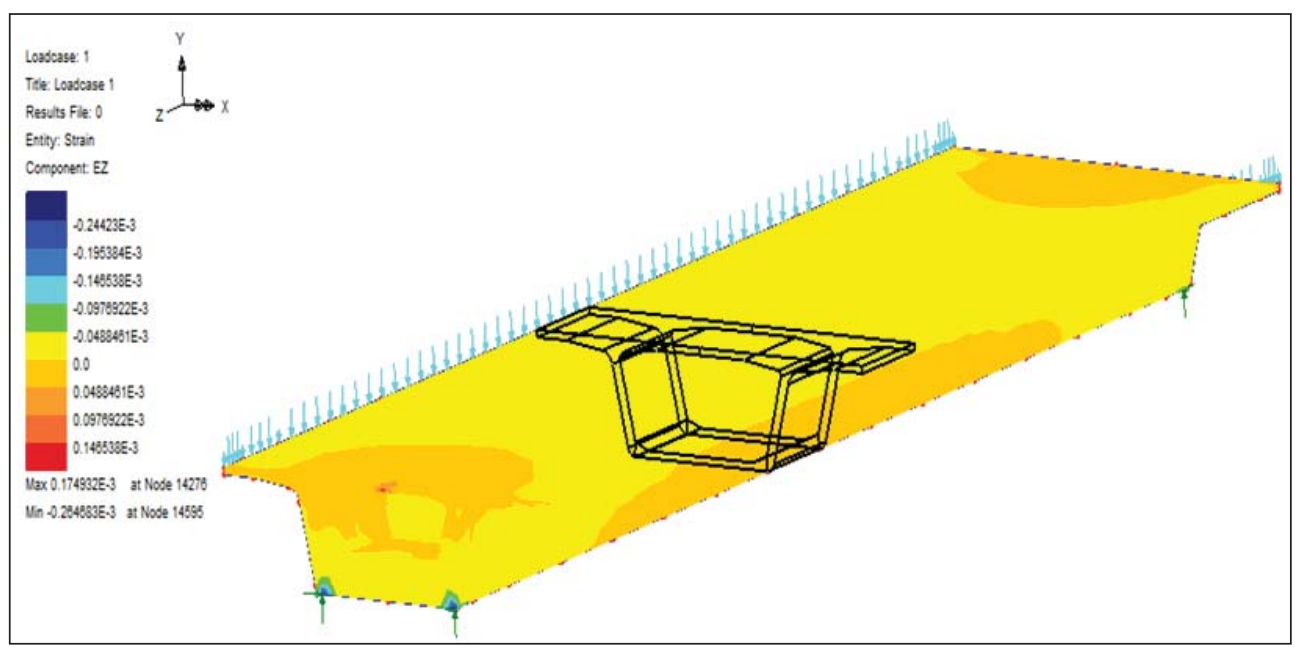

Figure 11: $L B_{\text {strain }}$ under $L C 1$ 


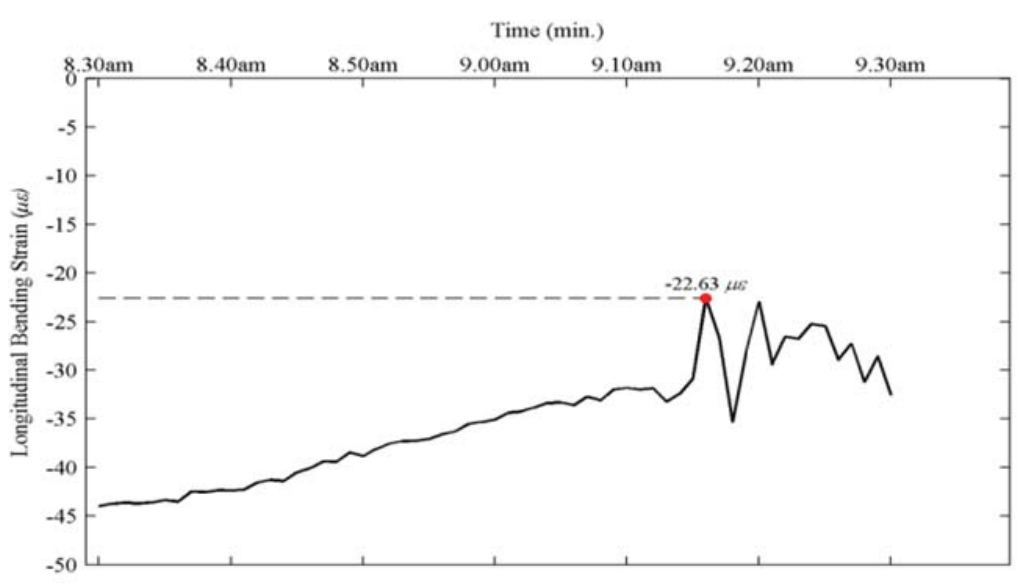

Figure 12: $L B_{\text {strain }}$ at bottom top slab (mid-span)

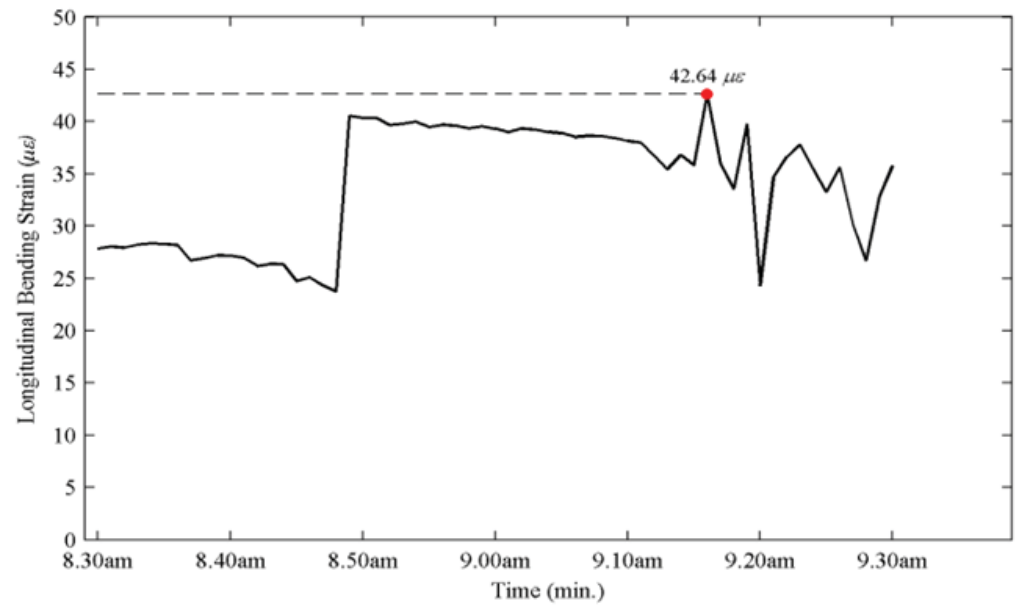

Figure 13: $L B_{\text {strain }}$ at bottom slab (mid-span)

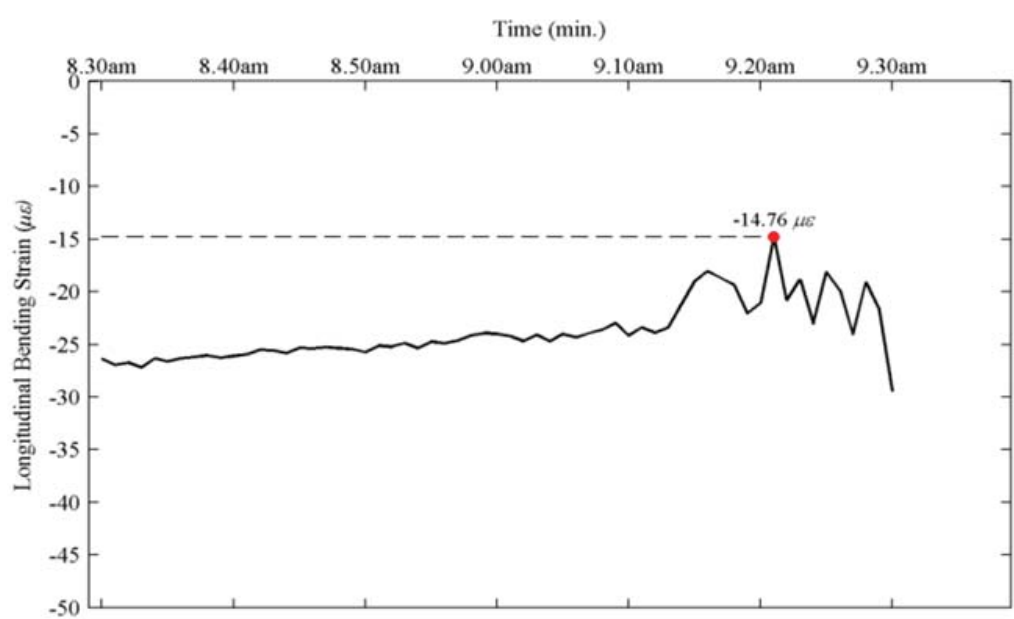

Figure 14: LBstrain at web (mid-span) 


\section{CONCLUSION}

It is often encountered in practice that the long-term deflections of pre-stressed bridges are greater than the deflections expected in the design. The excessive deflections might occur sometime after the completion. In this study, the short-term analysis was preferred because the precast SBG was yet to be opened to traffic at that time. The deterministic analysis of the bridge was carried out repeatedly for different input parameters, which enabled to quantify the phenomena for bridge deflection analysis especially for the calculation of the short-term deflection of a single span. All the modeling results were discussed and compared to the experimental data via static load test under three load cases, wherein only load case 1 was considered under parametric study. Consequently, short-term or instantaneous deflection, which was caused by elastic deformation of the concrete in response to loading occurred immediately upon load application. Based on the results of analysis, the following conclusions can be inferred:

- Study on elastic behavior of precast SBG showed that the experimental method was carried out successfully with the strains data monitoring recorded shows the strain and temperature profiles against time at mid-span area where the web, top, and bottom slab temperature increased and decreased with respect to the time and strain of the box sections (see Table 1). Based on the measured deck strains, the selected single span had responded to the specific load cases and subsequent unloading with measured behaviors and values that were very similar to the predicted value. The return of the observed values to the original values after the static load test confirmed the elastic behavior of the deck.

- The experimental work was carried out successfully with deck deflections data monitoring to ensure that no adverse deck responses to the loads will occur at any stage. It can be concluded that the actual deck responses under the three load cases were very similar to the respective theoretical expected deflections allowing for accuracy of the precise leveling and the theoretical values as reflected in both the patterns and the values. Furthermore, FEM is an acceptable method to obtain displacements and reactions for simply supported precast SBG under shortterm analysis. The displacement obtained by FEM compared with the experimental measures resulted in percentage errors which in the majority of the load cases were within $10 \%$ (see Table 2 ). The structural model of bridges constructed using simply supported method must adhere to the changes of boundary conditions. It should be emphasized that pre-stressing and parapets were completed but the pavement works had not yet started during the static load test and this should be considered depending on the current situation on site. Therefore, the underestimation of the deflections would be quite significant if ignored. It was also proven that when member was assumed and designed to be uncracked under full load, a simple linear elastic analysis based on gross cross-section was sufficient to give reasonable and realistic estimate of deflections.

- Referring to the parametric study for the different transversal slope under maximum deflection along the span length of precast SBG, the values that were obtained for $0 \%, 2.0 \%, 2.5 \%$, and $3.0 \%$ of transversal slope showed a slight difference between them (see Table 4). The calculated percentage error ranged from $0 \%$ to $10.28 \%$ under $2.5 \%$ transversal slope. The percentage error ranges that were less than $10 \%$ were considered acceptable. It can be concluded that the segmental bridge orientation was the stiffest among the four transversal slopes and the 3-D deck models cross-section will correctly define the shape, orientation, and position over the traditional method. Thus, it should be noted that the difference in transversal slope would affect the vertical displacements under short-term analysis and probably for deflection under long-term performance.

- Stress had an important role in precast SBG because it can affect the durability and strength of the structure. Higher stress will reduce the performance of a single span of precast SBG; thus, the stress at midspan area is important to be controlled. Stress also affected the value of shear capacity but it was not discussed in this study. From the calculated bending stress distribution, it can be concluded that in case of dead load and live load, effects during static load test was $22.1 \%$ higher in percentage error compared to FEM (see Table 3).

- The deflection of a bridge span was highly influenced by the behavior of cross-sections at the midspan and near the support zones. Moreover, a failure scenario normally occurs in these zones because of high strain level. Strain increased proportionally with increase in load. From the calculated bending strain distribution, it can be concluded that in case of dead load and live load, effects during static load test was $15.8 \%$ higher in percentage error compared to FEM (see Table 3).

Based on the measured deck displacements, stresses and strains, it can be concluded that the static load test and the parametric study made it possible to quantify the bridge deflections under short-term performance analysis. The good agreement between the theoretical calculations, LBM, experimental work, and FEM confirmed the quality of both the material used and the structural model. The transversal slope effect also had limitation and significance for bridge deflections. The results presented in this study will be a valuable guide to the designer and the owner of this bridge project for long-term monitoring or structural health monitoring (SHM) stage. This research had brought up many questions in need of further investigation. The static load test that was performed before 
bridge opening had to be verified routinely during operation and maintenance period under SHM stage in order to investigate the structural performance and the actual load carrying capacity of the bridge besides to provide information on either to rebuild or strengthen the bridge. The initial data included in the short-term analysis under 3-D FEM can be used by the owner. Therefore, the implementation via FEM under short-term analysis made its application easier and faster which was specifically devoted to the SHM stage.

\section{REFERENCES}

1. Design Manual for Roads and Bridges, TA/99 Volume 4 Section 2 (1999) for Surface Drainage of Wide Carriageways.

2. Hyo-Nam, C., Young-Min, C., and Byung-Choon, S. (1998). "Field Load Testing and Reliability-based Integrity Assessment of Segmental PC Box Girder Bridge before opening to traffic." Engineering Structures, Vol. 20, No. 11, pp. 948-956, DOI: 10.1016/ S0141-0296(97)00188-0

3. LUSAS version 14. FEA. Application Example Manual (Bridge, Civil and Structural).

4. Mathivat, J. (1983). The Cantilever Construction of Prestressed Concrete Bridges. A Wiley-Interscience Publication, John Wiley \& Sons, Inc, New York, NY.

5. Zhou et al. (2011). Static Test Analysis of a Bridge Structure in Civil Engineering. International Conference on Risk and Engineering Management (REM), Vol. 1, pp. 10-15, DOI: 10.1016/j.sepro.2011.08.003. 